\title{
A HYBRID MODEL OF SWASH-ZONE LONGSHORE SEDIMENT TRANSPORT ON REFLECTIVE BEACHES
}

\begin{abstract}
Angela Wenping Jiang ${ }^{1}$, Michael Hughes ${ }^{1}$, Peter Cowell ${ }^{1}$, Angus Gordon ${ }^{2}$, Juan Carlos Savioli $^{3}$ and Roshanka Ranasinghe ${ }^{4}$

The hydrodynamics and sediment transport in the swash zone is currently outside the domain of coastal-area models, which is a significant limitation in obtaining littoral sediment-transport estimates, especially on steep reflective beaches where the waves practically break on the beachface. In this study, an existing process-based coastal model (MIKE 21) is combined with a theoretical derivation of swash processes, resulting in an innovative hybrid modelling approach that is capable of estimating longshore sediment transport in the swash zone. The method relies upon estimation of swash hydrodynamics from an extended ballistic swash model with friction included. The terminal bore and other incident wave properties were computed from the output of a spectral-wave model (MIKE $21 \mathrm{SW}$ ). The Bagnold-type equation was applied to estimate gross transport volumes and the longshore component was computed for the sand volume displaced during the up-rush. The newly developed hybrid modelling approach was applied to Jimmys beach, a steep reflective beach $\left(D_{50}=0.3 \mathrm{~mm}\right.$, gradient $\left.=0.1\right)$ along the northern shoreline of Port Stephens, Australia. The model results yield the alongshore swash transport pathways and the indicative transport volumes. A point of divergence is identified at the beach erosion area, which is of critical importance in terms of shoreline erosion and management. The preliminary results suggest that swash-zone transport can account for a large percentage of the total littoral drift for such beaches. However, further field or laboratory data are required to test model utility, as well as to tune calibration parameters based on the site-specific conditions.
\end{abstract}

Keywords: swash zone; wave up-rush; longshore sediment transport; reflective beaches; numerical modeling.

\section{INTRODUCTION}

Quantitative prediction of coastal processes and coastal evolution via numerical modeling is now possible due to the major advances that have been made in understanding physical processes and mathematical modeling techniques over the last few decades. However, hydrodynamics and sediment transport in the swash zone is currently outside the domain of even the most state-of-the-art coastalarea models, which is a significant limitation in obtaining littoral sediment-transport estimates on steep reflective beaches due to their direct contributions to beachface morphodynamics especially at short time scales. In this study, an existing process-based coastal model (MIKE 21) is combined with a theoretical derivation of swash processes, resulting in an innovative hybrid modelling approach that is capable of estimating longshore sediment transport in the swash zone.

The swash zone is the part of the beach between the minimum wave run-down (backwash) and maximum wave run-up (uprush), and constitutes a beach area where waves dissipate or reflect their remaining energy after travelling towards the shore (Larson et al., 2004). The swash zone is characterised by strong and unsteady flows, high turbulence levels, large sediment transport rates and rapid morphological change (Puleo et al., 2000), and represents arguably the most dynamic region of the nearshore (Masselink and Puleo, 2006). While sediment transport mechanisms in the surf zone are well established, the importance of swash zone processes has just received increasing attention in recent years. It is now acknowledged that swash zone sediment transport processes are important for two main reasons. Firstly, the water motion within the swash zone provides the principal mechanism for cross-shore sediment exchange between the sub-aerial and sub-aqueous zones of the beach (Masselink and Hughes, 1998). Offshore and onshore sediment transport in the swash zone, therefore, contributes significantly to shoreline accretion and erosion. Secondly, a significant part of the longshore sediment transport occurs in the swash zone and may account for a large portion of the total littoral drift (Bodge and Dean, 1987, Kamphuis, 1991, Smith et al., 2009), especially on steep reflective beaches (Van Wellen et al., 2000), where the surf zone is typically narrow or even absent, with wave breaking occurring practically on the beachface. Alongshore sediment transport in the swash zone can be significantly greater than that in the surf zone on such beaches (Hughes et al., 2007).

\footnotetext{
${ }^{1}$ School of geosciences, University of Sydney, Camperdown, NSW 2006, Australia

${ }^{2}$ Coastal Zone Management \& Planning, North Narrabeen, NSW 2101, Australia

${ }^{3}$ DHI Water \& Environment, Petaling Jayas, Selangor 46350, Malaysia

${ }^{4}$ UNESCO-IHE/Technical Univ. of Delft, 2601 DA Delft, The Netherlands
} 
Previous theoretical and empirical studies have made some progresses in understanding swashzone hydrodynamics and sediment transport. The first order, non-linear shallow water theory has been applied to obtain solutions for swash-zone hydrodynamics, whilst estimates of sediment transport are mainly based on either energetics-based equations proposed by Bagnold (1963, , 1966) or Shields-type formulas proposed by Meyer-Peter and Muller (1948). Despite the complexity of the processes and the logistical difficulty in performing high-quality field measurement (Elfrink and Baldock, 2002), a number of field and laboratory studies have made considerable efforts to verify the analytical models (e.g., Baldock et al., 2008, Hughes et al., 2007, Hughes and Baldock, 2004, Masselink and Hughes, 1998). Butt and Russell (2000) summarised field and experiment studies of swash-zone hydrodynamics, resulting sediment transport mechanism, and associated modelling concepts. A more comprehensive review of conceptual and mathematical models applied in the swash zone can be found in Elfrink and Baldock (2002) and Bakhtyar et al. (2009). They both conclude that none of the deterministic models can resolve all potentially important aspects of the flow and sediment transport in the swash zone.

\section{THEORITICAL BACKGROUND}

\section{Swash Hydrodynamics}

Shen and Meyer (1963) first applied the Non-Linear Shallow Water Equations (NLSWE) to obtain solutions for bore propagation, shoreline displacement, shoreline velocity, swash height and geometry of the swash lens. Field and laboratory studies (e.g., Baldock and Holmes, 1997, Hughes, 1992) have examined and verified the implications of this theoretical work. It was found that the analytical solution describes inviscid shoreline motion qualitatively accurate, but the swash depths and the maximum shoreline run-up were significantly over predicted and the shape of the swash lens was observed to be convex rather than concave. Subsequently, Baldock and Holmes (1997) proposed a semi-empirical similarity formulation for the swash depth that more closely approximates experimental observations. Meanwhile, a number of researchers have refined the analytical model by incorporating a quadratic friction law applied to the moving shoreline (e.g., Freeman and Lemehaute, 1964, Holland and Puleo, 2001, Hughes, 1992, Kirkgöz, 1981) to account for energy dissipation due to the bed friction, as well as to accommodate the asymmetrical nature of up-rush/backwash flow durations and velocities, which is a key feature of swash kinematics identified by field and laboratory studies (e.g, Baldock and Holmes, 1997, Kemp, 1975, Raubenheimer et al., 1995). Having obtained the shoreline motion and the flow depths within the swash lens, the depth-averaged Eulerian flow velocity at any fixed location on the beachface can be calculated based on the mass balance principle. These findings have been integrated to develop an extended ballistic swash kinematics model in a field and numerical model study (Hughes and Baldock, 2004). Verification against field measurements has shown that the ballistic swash model can successfully predict shoreline motion, maximum run-up, and more importantly, Eulerian flow velocities during individual swash events.

In an inviscid flow, Shen and Meyer (1963) showed that for fully developed turbulent bores the shoreline motion depends only on the bore velocity upon arrival at the initial shoreline position, which subsequent laboratory experiments have shown is accurate (Yeh et al., 1989). The motion of the front of the swash lens (moving shoreline) and some details of the flow within the swash lens can be determined from a set of assumptions and corollaries of the NLSWE. Ho et al. (1963) described a useful way to visualize the mathematical arguments by imagining that the swash lens consists of several small fluid elements, each containing the same mass of water at all times. The motion of each fluid element depends only on the pressure exerted by the adjacent elements and gravity. Freeman and Lemehaute (1964) argued that the swash lens is analogous to a rarefaction wave; thus the leading element is always moving faster than the elements behind, and the pressure acting on it will be negligible. The problem of the shoreline climbing the beach therefore simplifies to a consideration of the balance of forces acting on the leading element alone. Assumptions relating to the nature of the fluid are the same as those that are valid for the NLSWE. It is further assumed that the wave period is sufficiently long to ensure no backwash interaction occurs and that the beach face is hydraulically smooth and impermeable. The equation of motion for the leading edge of the swash lens or moving shoreline can be written as:

$$
m \frac{d^{2} X_{s}}{d t^{2}}+m g \sin \beta=0
$$


Where $m$ is the mass of the leading fluid element, $X_{s}$, is its position relative to the initial shoreline position, $g$ is the gravitational acceleration and $\beta$ is the beach face slope. Through integration and adopting the initial condition that $d X_{s} / d t=u_{o}$ when $t=0$ the shoreline velocity, $U_{s}$, is obtained;

$$
\frac{d X_{s}}{d t}=U_{s}(t)=u_{0}-g t \sin \beta
$$

Since the shoreline displacement is zero when $t=0$, integration of (2) yields the time history of the shoreline position:

$$
X_{s}=U_{0} t-\frac{1}{2} g t^{2} \sin \beta
$$

Furthermore, when $t=T_{s}$ (swash period), the shoreline is back at the initial position $X_{s}=0$. Thus, the terminal bore velocity $u_{0}$, which is equal to the shoreline velocity $U_{0}$, can be written as:

$$
u_{0}=U_{0}=\frac{1}{2} T_{s} g \sin \beta
$$

The bore collapse involves the rapid conversion of potential energy to kinetic energy, with an associated acceleration of the fluid velocity at the bore front (Yeh et al., 1989). Therefore, a classical dam-break equation gives the relationship between the initial bore height $H_{b}$ and velocity $u_{0}$ :

$$
u_{0}=2 \sqrt{g H_{b}}
$$

For simplicity, the initial bore height $H_{b}$ and velocity $u_{0}$ can be derived from Eq (4) and (5) once the swash period is known, which is slightly inaccurate if the effects of friction and infiltration are accounted for.

A field study by Hughes (1992) has shown that the inviscid form of the equations achieved qualitative agreement between theoretical swash motions and observed data, but the swash depths and the maximum shoreline run-up were significantly over predicted. This over prediction was attributed to the absence of friction and infiltration in the inviscid theory, given that the swash depths are small and hence the effects of friction and infiltration are pronounced. By incorporating a shear stress term in the force balance at the leading edge, factors other than friction, such as infiltration, are inherently included as phenomena that act to reduce fluid momentum (Puleo and Holland, 2001). The typical approach to include the friction due to a bed shear stress, $\tau$, is to apply the quadratic stress law using the flow velocity:

$$
\tau=\frac{1}{2} \rho f \frac{d X}{d t}\left|\frac{d X}{d t}\right|
$$

Where $\rho$ is the fluid density, $f$ is the friction factor, and $d X / d t$ is the shoreline velocity. Incorporating equation (6) into (1) and dividing throughout by $m=\rho \delta^{2}$ ( $\delta$ is a length scale for the fluid element representing the shoreline) yields:

$$
\frac{d^{2} X_{s}}{d t^{2}}+g \sin \beta+\frac{f}{2 \delta} \frac{d X}{d t}\left|\frac{d X}{d t}\right|=0
$$

If $g, \beta, f$, and $\delta$ are assumed to be constant, then equation (7) can be solved analytically for the shoreline position $X_{s}$ through time. The initial conditions at $t=0$ are: (1) The shoreline velocity, $U_{0}=$ $d X / d t$, is equal to the terminal bore velocity $u_{0}$, and (2) the shoreline position $X_{s}$ is located at $x=0$. Integrating equation (7) twice using separation of variables yields the shoreline position during the uprush $X_{u}$ (Kirkgo“"z, 1981; Hughes, 1995),

$$
X_{u}=\frac{2 \delta}{f} \ln \left[\frac{\cos (A t+B)}{\cos B}\right]
$$

Where 


$$
A=-\sqrt{\frac{g f \sin \beta}{2 \delta}}, B=\tan ^{-1}\left(\frac{u_{0} \sqrt{f}}{\sqrt{2 g \delta \sin \beta}}\right)
$$

Eq (8) is only valid until the shoreline reached its maximum displacement landward $X_{\max }$ when $d X_{u} / d t=0$. Hughes (1995) derived $X_{\max }$ and the time that this occurs, $t_{\max }$ (equivalently the up-rush duration $T_{u}$ ) as:

$$
\begin{gathered}
X_{\max }=\frac{-2 \delta}{f} \ln (\cos B) \\
T_{\max }=B / A
\end{gathered}
$$

The shoreline position during the backwash is also obtained from equation (7). The initial conditions at $t=0$ for the backwash are: (1) The shoreline velocity is equal to zero, and (2) the shoreline position $X$ is again defined as $x=0$. Again, integrating equation (7) twice yields the shoreline position during the backwash $X_{b}$, which measured relative to $X_{\max }$ is (Holland and Puleo, 2001):

$$
X_{b}=\frac{-2 \delta}{f} \ln [\cos A t]
$$

Note that the values of $f$ and $\delta$ may differ during the up-rush and backwash. For simplicity, equations (8) and (12) assume a plane slope within the swash zone.

The swash depth $h$ can be obtained from a semi-empirical formulation proposed by Baldock and Holmes (1997):

$$
h(x, t)=H_{b}\left(\frac{X-x}{X}\right)^{C}\left(\frac{T_{s}-t}{T_{s}}\right)^{D}
$$

The terminal bore height $H_{b}$ can be obtained from equation (5) provided that swash period, $T_{s}$ is known. $C$ and $D$ are empirical coefficients that control the shape of the swash lens and the rate of thinning of the swash lens respectively. Equation (13) is based on the following constraints: (1) when $(X-x)<=0$, then $h=0$; (2) when $x=0$ and $t=0$, then $h=H_{b}$; and (3) when $x=0$ and $t=T_{s}$, then $h$ $=0$ (i.e., the water depth is equal to the height of the incident bore at the start of the up-rush, $x=0$, reducing to zero at the end of the backwash and at the run-up tip). This formulation assumes that individual non-interacting swash events have a similar water surface profile, dependent on fixed choices of $C$ and $D$ for particular wave conditions and beach slope.

An estimate of the depth averaged Eulerian flow velocity $u(t)$ at any fixed location of interest $x=$ $x_{i}$ on the beach face can be obtained using the mass balance principle (neglecting infiltration/exfiltration), where the discharge of water $\mathrm{Q}$ (per unit width of beach) that passes $x_{i}$ is (Hughes, 1989; Turner and Masselink, 1998; Peregrine and Williams, 2001):

$$
Q=\frac{V}{t}=h u
$$

The volume of water shoreward of the fixed location of interest $x=x_{i}$ is

$$
V=\int_{x_{i}}^{X} h(x) d x
$$

Re-arranging equation (14) and expressing it in finite difference form yields the following equation for the Eulerian flow velocity $u$ at $x=x_{i}$ :

$$
u=\frac{V(t+\Delta t)-V(t-\Delta t)}{2 h(t) \Delta t}
$$

Where $h(t)$ is obtained from equation (13) and $V(t \pm \Delta t)$ is obtained from equation (15). 


\section{Swash Zone Sediment Transport}

Field studies (e.g., Hughes et al., 1997) have shown that the measured immersed weight total load transport rate displayed a strong relationship with the cube of time-averaged velocity, which is consistent with equations for both bedload transport and total load transport under sheet flow conditions. Consequently, the Bagnold- and Shield-type of model have been frequently validated in field and laboratory studies (e.g., Hardisty et al., 1984, Hughes et al., 1997, Masselink and Hughes, 1998, Nielsen, 2002, Van Wellen et al., 2000). Here, the Bagnold-type equation is of particular relevance, since bed slope is represented in the transport equation (Eq. 17). As Hughes et al. (1997) point out that, the major indicator of morphological change in the beach environment is a change in beach slope. This simplifies the simulation of such morphodynamic phenomenon as the equilibrium balance between hydrodynamic asymmetry and gravity on the beach face (e.g., Hardisty, 1986, Turner, 1995), which can be used to explain the often reported relationship between beach slope and wave/sediment characteristics (e.g., Sunamura, 1984, Wright and Short, 1984). For this reason the Bagnold-type eneregetics equations are used in this study to estimate sediment transport in the swash zone as follows:

$$
I_{u}=\frac{k \bar{u}^{-3} T_{u}}{\tan \phi+\tan \beta}
$$

where $I_{u}$ is the immersed weight sediment transport per unit meter beach width $(\mathrm{kg} / \mathrm{m})$ during uprush, $k$ is a calibration coefficient $\left(\mathrm{kg} \mathrm{m}^{-3}\right), \bar{u}$ is the time-averaged flow velocity $(\mathrm{m} / \mathrm{s}), T_{u}$, is the uprush duration, $\phi$ is the friction angle of the sediment $(\tan \phi=0.63)$ and $\beta$ is the beach slope. Thus, the flux volume is:

$$
q(x)=\frac{I_{u}(x)}{(1-\varepsilon)\left(\rho_{s}-\rho\right)}
$$

Where $\rho_{s}$ and $\rho$ are the densities of sand and sea water respectively, and $\varepsilon$ is the sand porosity when deposited.

\section{MODEL DEVELOPMENT}

In the present study, an existing process-based coastal model (MIKE 21) is combined with a theoretical derivation of swash processes, resulting in an innovative hybrid modelling approach that is capable of estimating longshore sediment transport in the swash zone. The method draws from a simplified adaptation of theoretical work on swash-zone sediment transport described above. By assuming the classical zigzag swash-drift pattern for incident waves arriving at an angle to the beachface, the net longshore component is computed for the sand volume displaced during the up-rush (the net longhsore component being zero during the backwash phase).

\section{Swash Zone Sediment Transport Calculation}

Swash oscillations can be driven by infragravity waves, edge waves or incident waves according to the most energetic wave frequency operating in the inner surf zone (Hughes, 1992). This study specifically addresses swash produced by incident waves at reflective, sandy beaches. In general, surging waves predominantly occur at low-energy reflective beaches, with the wave crest surging up and collapsing upon the beachface to produce swash. Swash oscillations are directly associated with the uprush and backwash of incident waves, and have periods typically between 5 and $15 \mathrm{sec}$ (Bradshaw, 1980). Thus, swash period is assumed to be equal to wave period. Provided that the wave period can be obtained from the SW model output, the initial bore velocity and height were calculated using Eq. (4) and (5). Further apply Baldock and Holmes's semi-empirical formulation, Eq. (13), together with Eq. (15) and (16), yield the Eulerian flow velocity at any fixed point. Eventually, the gross sediment transport rate was obtained from the Bagnold-type equation (17).

Longshore drift on the beach face can be regarded as the alongshore component of runup and backwash-driven sand transport (Fig. 1a). Although swash trajectories are now generally represented as parabolic paths, the classical and simplest representation is of a saw-tooth pattern in which the runup path is determined by the incident angle of waves arriving at the beach face, while the backwash draws straight down the beach, perpendicular to elevation contours, under the action of gravity alone (Fig. 1b). The implication of the classical saw-tooth swash trajectory is that the alongshore component is determined exclusively by the runup phase of swash motion: i.e., the backwash can therefore be 
ignored. Ignoring the alongshore component of the backwash phase associated with parabolic swash trajectories implies that sand-transport rates obtained from a saw-tooth model would be minimum estimates of longshore-drift.

A simplified approximation of longshore drift rates can be obtained from the shore-parallel component, $\bar{q}_{y}$, of the estimated average sand flux up the beachface, $q$, due to wave runup:

$$
\bar{q}_{y}=\bar{q} \cos \alpha
$$

Where

$$
\bar{q}=\frac{1}{L \sin \alpha} \int_{0}^{X} q d x
$$
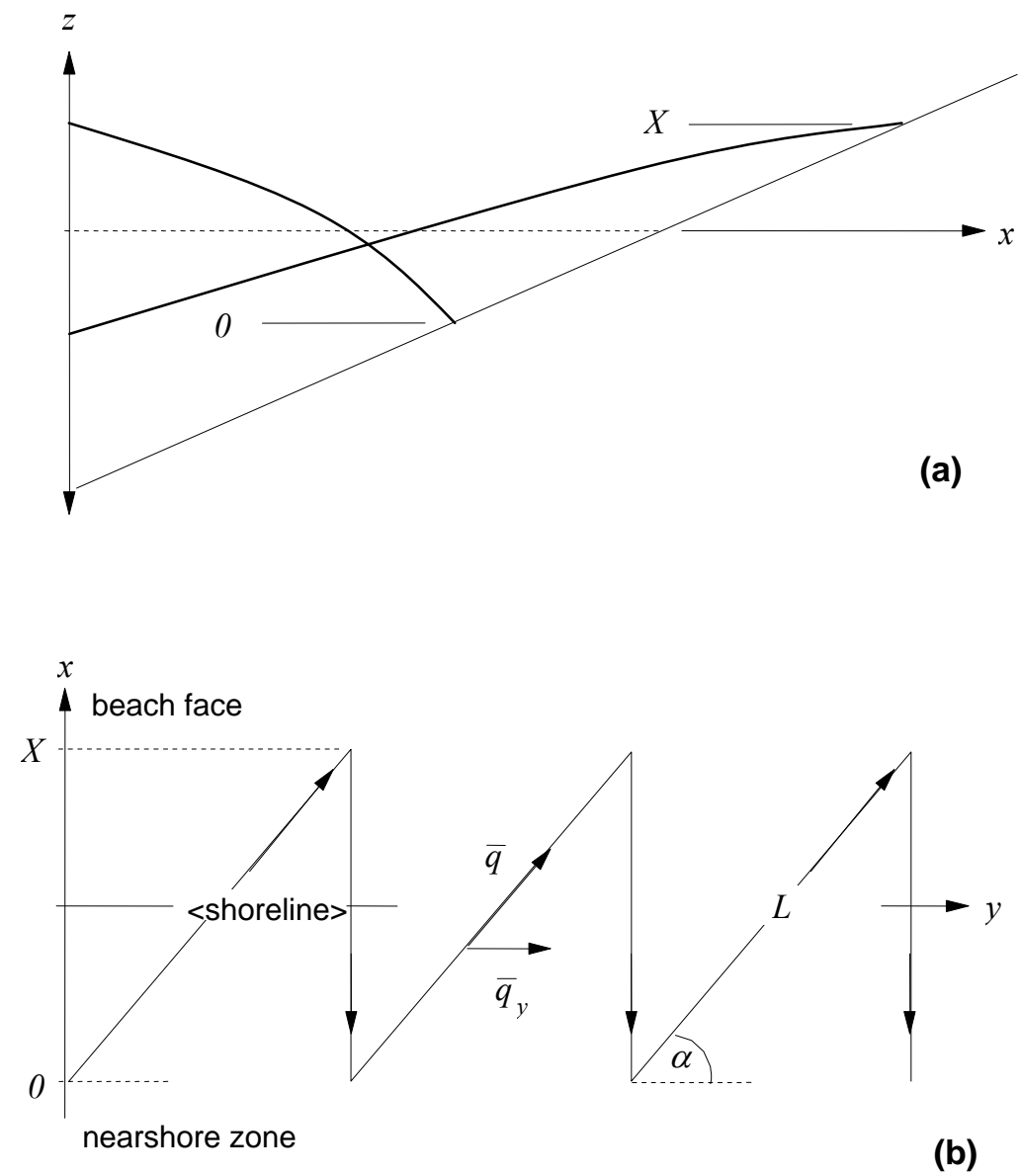

Figure 1 Schematic swash trajectory and shore-parallel component of sand transport due to wave runup: (a) vertical section across beach; (b) alongshore swash path.

Fig. 2 shows the hybrid model components and the sequence in which the modules of the system are implemented. The modeling approach requires beach slope and wave period to calculate the terminal bore velocity (Eq. 4) and incident wave angle to calculate the longshore transport component (Eq. 19). The beach slope was obtained from field measurements and wave angle was calculated from the shoreline orientation and mean wave direction obtained from a wave propagation model (MIKE 21 SW). 


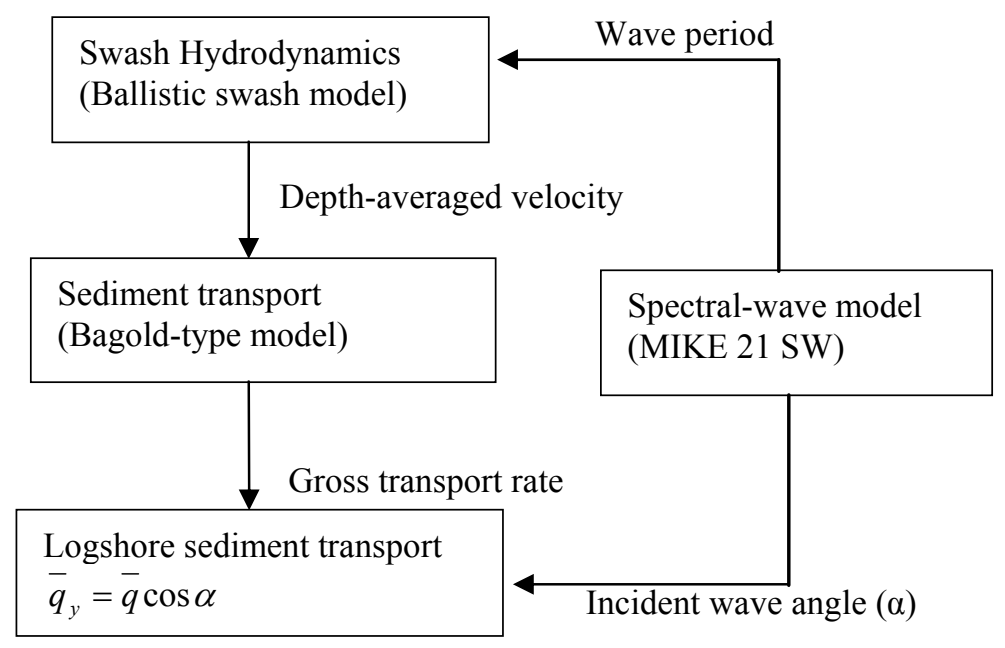

Figure 2 Schematic showing the model components combined to estimate longshore sediment transport for a single uprush.

\section{MODEL APPLICATION}

\section{Study Site}

The modeling approach described above was applied to a reflective beach with chronic erosion problems. Jimmys Beach is an estuarine beach along the northern shoreline of Port Stephens, which is a drowned river valley estuary, located on the central coast of New South Wales (NSW), Australia (Fig. 3). The central NSW coast is characterised as a moderate to high energy swell regime with $63 \%$ of swell in the range of 1-2 $\mathrm{m}$, and a further $21 \%$ in the 2-3 m range (Short and Trenaman, 1992). Annual average significant wave height is $1.64 \mathrm{~m}$ with a period of $9.57 \mathrm{~s}$ (Lord and Kulmar, 2000). Port Stephens is open to the Pacific Ocean between two headlands, and hence is subjected to swell energy mostly from $\mathrm{E}$ to $\mathrm{S}$ sector. However, after undergoing wave shoaling, refraction and diffraction before reaching the beach, ocean waves are attenuated to about $22 \%$ of the offshore wave heights at Jimmys Beach (measured $160 \mathrm{~m}$ offshore of the beach) (PWD, 1987). Jimmys Beach is described as a steep reflective beach with a narrow beach berm backed by a pronounced erosion escarpment (gradient $\approx 0.1$ ). Grain size sampled on the beachface is in the medium sand range with a $D_{50}$ of about $0.3 \mathrm{~mm}$. The field site also offers a distinct advantage for this study in that sea grass beds are present immediately offshore from the swash zone along much of the beach. These conditions increase the likelihood that most of the alongshore transport is confined to the swash zone.

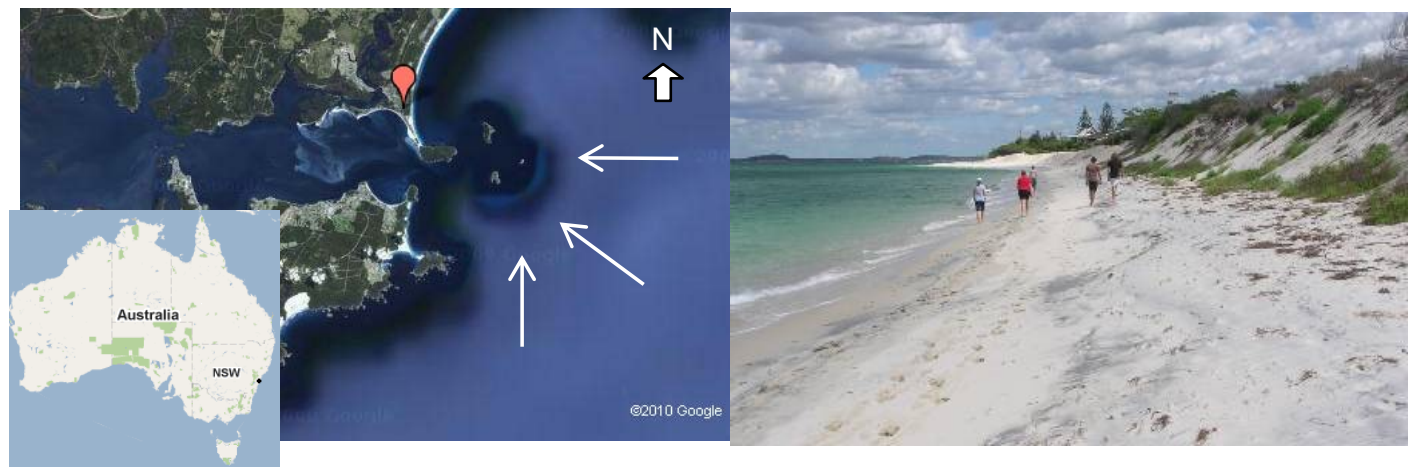

Figure 3 Location of Port Stephens, offshore wave conditions in the area and a photo of Jimmys Beach showing the narrow beach berm backed by an erosion escarpment.

\section{Wave Transformation Module}

In this study, MIKE 21 Spectral-Wave module (SW) developed by DHI Water \& Environment was used to transform offshore waves to nearshore area. It is a state-of-the-art numerical model for 
simulating the growth, decay and transformation of wind-generated waves and swells in offshore and coastal areas (DHI, 2008).

The wave transformation model based on an unstructured flexible mesh was set up for the study site. A computational mesh with spatially varying solutions was applied (shown in Fig. 4). A coarse resolution (200-300 m) was used for the regional scale part while a high-resolution (50-150 m) was applied for the area of interest. Specifically, in the nearshore area, an enhanced resolution of 10-20 m nodal spacing was specified.

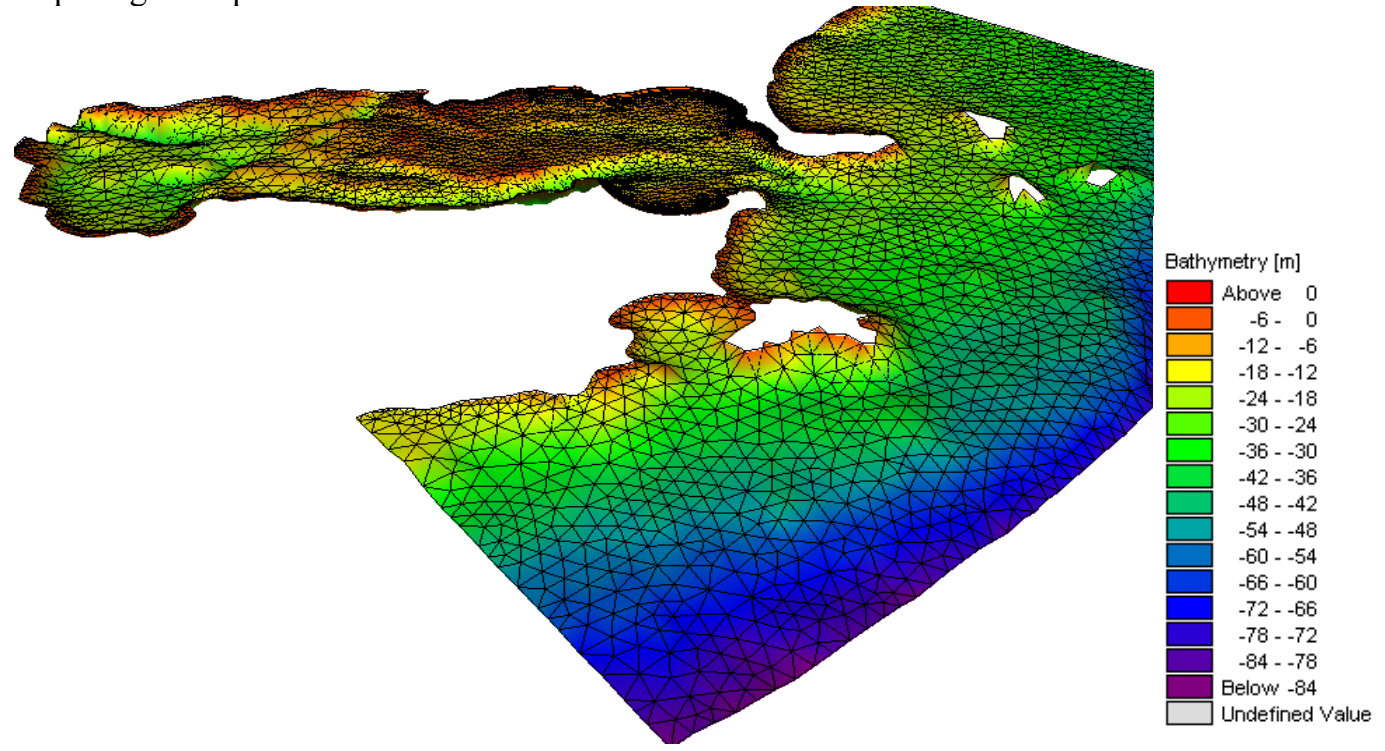

Figure 4 Bathymetry and computational mesh of the MIKE 21 SW model.

The model was calibrated and validated against wave data collected at two nearshore locations at Jimmy's Beach and Shoal Bay at Port Stephens. Due to limited field data, the comparisons were not subjected to statistical analyses. However, the graphical comparisons (Fig. 5) show that the model results agree well with measured wave data.
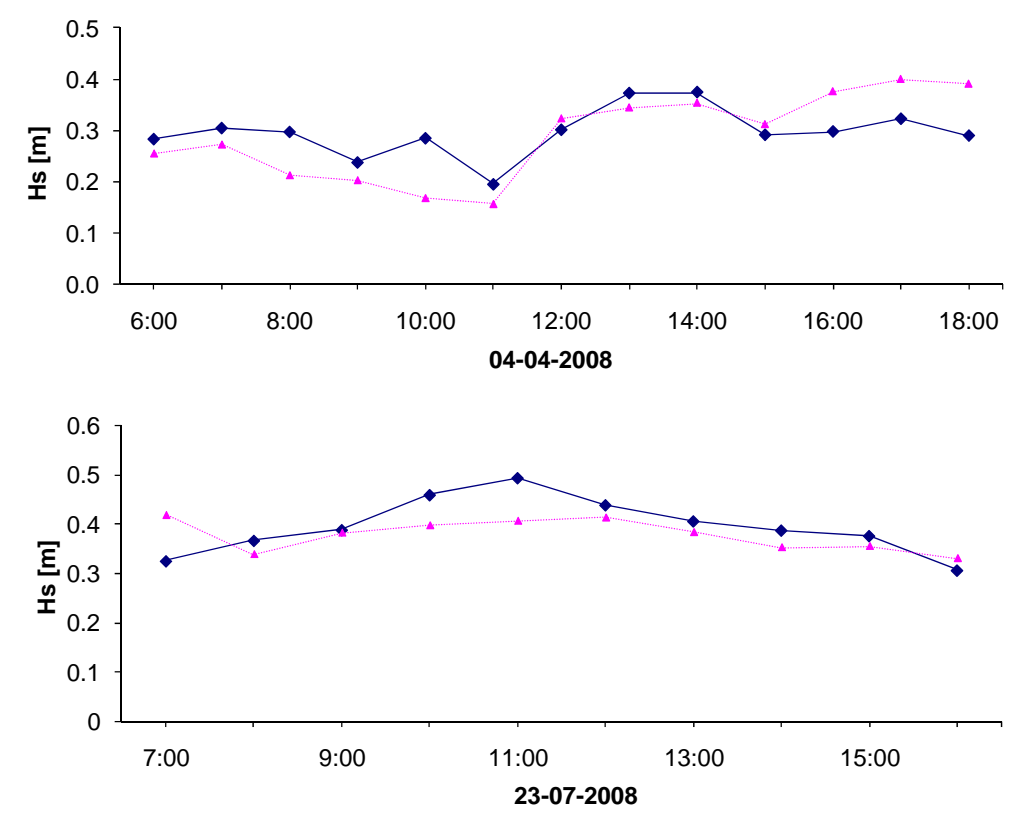

Figure 5 Comparison of measured (solid) and modelled (dash) significant wave height at Port Stephens. 


\section{RESULTS}

The model calculated up-rush behaviour driven by a typical $6 \mathrm{~s}$ swash event is described in Fig 6 , including the time series of the swash profiles in terms of depth and Eulerian flow velocities at a fixed point during a single swash run-up. The time step interval is $0.1 \mathrm{~s}$ with a grid size of $0.1 \mathrm{~m}$. As a first approximation, some empirical values were adopted based on the similarities of related site-specific characteristics, i.e. beach slope, grain size, etc. In the semi-empirical function (Eq.13) describing the swash depth, the empirical coefficients $C=0.75$ and $D=2$ were adopted, in accordance with a laboratory study which reported that these values resulted in a good approximation of the swash lens for a steep beachface with a gradient=0.1 (Baldock and Holmes, 1997). The friction coefficient for uprush (required when calculating $X$ in Eqn. 13) was taken to be within the range of 0.02-0.06 based on field observations (Raubenheimer et al., 2004). The coefficient $k$ in the Bagnold equation was taken as $1.37 \mathrm{~kg} \mathrm{~m}^{3}$ based on a previous field study on a beach with the same grain size as the study site (Hughes et al., 1997).

The swash profiles and non-linearly reducing velocities indicate a good agreement with swash behaviour described in theory and verified by field and laboratory data (e.g., Hughes and Baldock, 2004, Shen and Meyer, 1963)
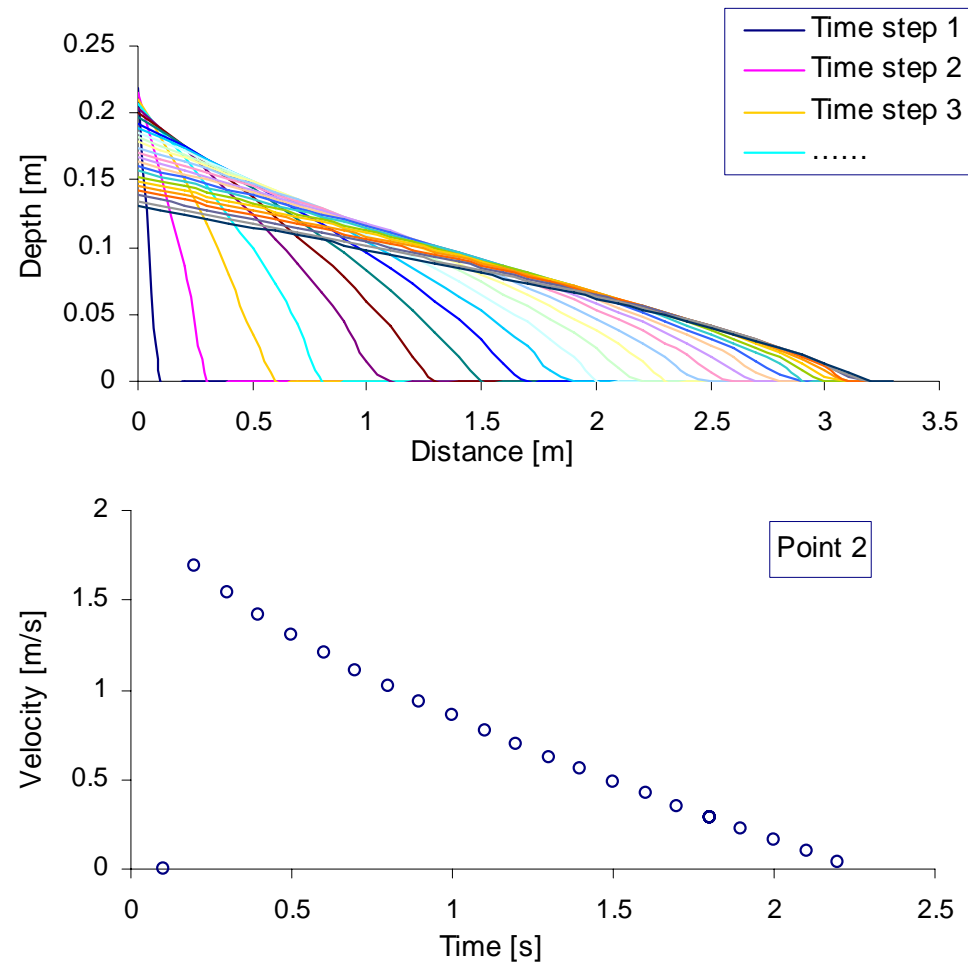

Figure 6 Calculated swash profiles and the Eulerian flow velocities at a fixed point during a single up-rush.

As an initial application, the model was applied with 10\% AEP ocean wave conditions, i.e., E wave $\left(H_{s}, T_{01}=1.5 \mathrm{~m}, 8.0 \mathrm{~s}\right)$, SE wave $\left(H_{s}, T_{01}=1.8 \mathrm{~m}, 10.5 \mathrm{~s}\right)$, and $\mathrm{S}$ wave $\left(H_{s}, T_{01}=2.1 \mathrm{~m}, 9.8 \mathrm{~s}\right)$. Fig. 7a shows the 287 computational elements along Jimmys Beach from western end of Barnes Rocks to the eastern end of the beach. Computed alongshore swash drift are shown in Fig.7b. Positive value indicates a westward drift while negative value indicates an eastward drift. Model results reveal the alongshore swash transport pathways as well as the indicative transport volumes alongshore. The peak rate occurs at the element 34 with a westward direction. The element 48 is identified as a point of sediment transport divergence. Between element 48 and 101, the transport is directed eastward, followed by a stable area (102 to 132) and then changes to westward with increasing transport rate to the eastern end of the beach.

The results also indicate that waves from different directions propagating into the estuary between the two headlands, which act as a filter, result in the similar wave directions at Jimmys Beach. Thus it can be stated that wave-driven alongshore swash drift pathway is not sensitive to the offshore wave directions as it totally depends on the incident wave angle formed by wave direction and beach orientation. 
Model predicted sediment transport volumes were also compared with the total littoral drift rate using the data collect by a previous study (PWD, 1987). The total transport rate was measured at the erosion area (around element 72) using sand traps deployed on the beachface and extended to approximately $5 \mathrm{~m}$ seaward of mean low water. Measured accumulation of sand against the trap was about $1.67 \mathrm{E}-04 \mathrm{~m}^{3} / \mathrm{s}$ under a swell wave of $9.9 \mathrm{~s}$. The model calculated alongshore swash-zone transport rate at the same location as measurements is in the range of $5.67 \mathrm{E}-0.5$ to $40.9 \mathrm{E}-05 \mathrm{~m}^{3} / \mathrm{s}$ depending on the bed friction factor adopted (0.02-0.06). Thus, model predicted alongshore swashzone transport may account for $34 \%-100 \%$ of the total littoral drift under the wave conditions simulated at the study site.

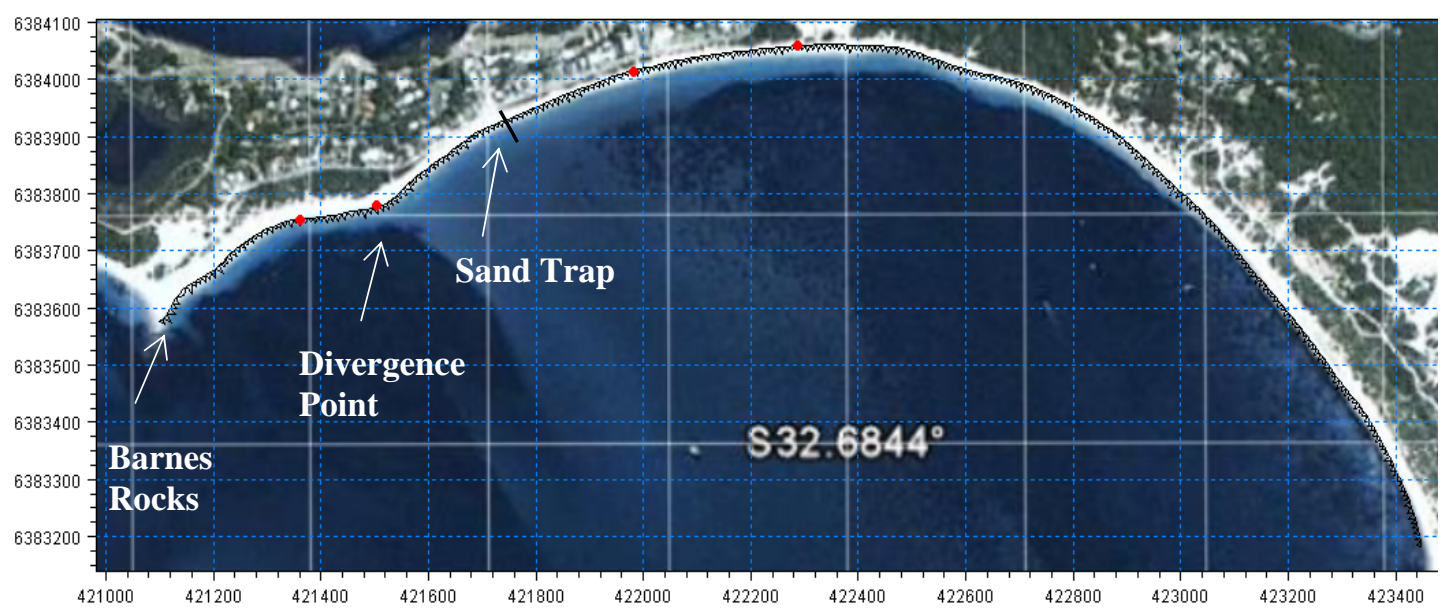

(a)

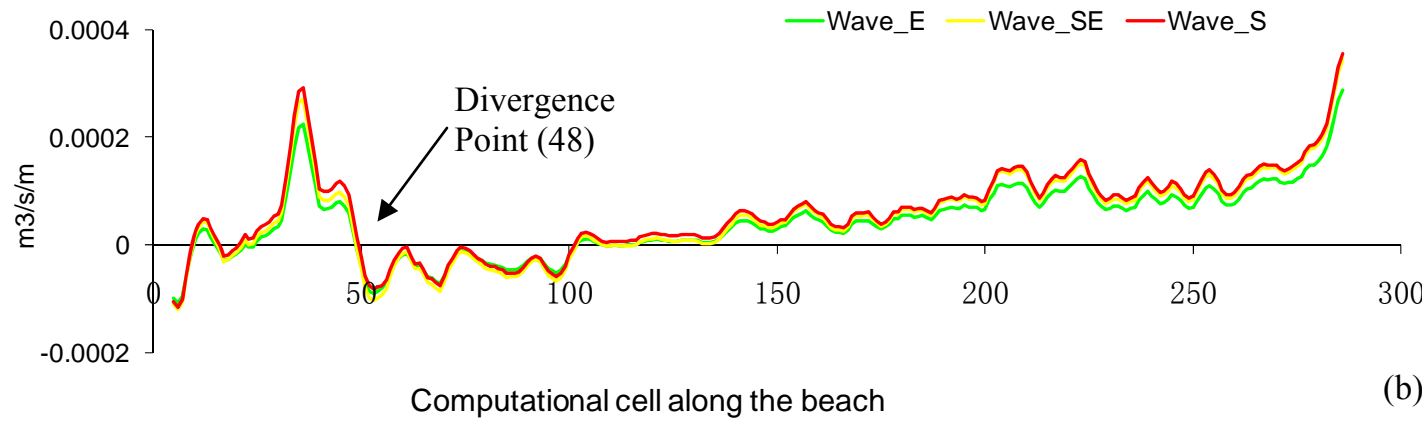

Figure 7 (a) Computational elements along Jimmys Beach with elements 34, 48, 101 and 132 marked (west to east); (b) Calculated alongshore swash drift for Jimmys Beach under 10\% AEP wave conditions with positive value indicating a westward drift while negative value indicating an eastward drift.

\section{DISCUSSION}

The model developed here involves a number of simplifications of the physical processes, tentatively, given the paucity of swash zone studies. The major assumptions are: (1) Swash oscillations are directly associated with the uprush and backwash of incident waves $\left(T_{s}=\right.$ wave period), and hence swash interaction was not accounted for; (2) The beachface is planar and impermeable, that is, infiltration/ex filtration is not included; (3) Sediment transport during the uprush phase occurs predominantly bedload, or as sheet flow, under which bedload is assumed to be the principle transport mode; (4) The parabolic swash trajectory is simplified as a classical saw-tooth pattern, in which the run-up path is determined by the incident angle of waves arriving at the beach face, while the backwash draws straight down the beach, perpendicular to the shoreline.

The shoreline motion described by the ballistic model is an analytical solution to the onedimensional, depth-averaged, nonlinear shallow water equations (NLSWE), which is applicable to bores approaching the shoreline, but it cannot account directly for interactions between swash events. It is therefore most applicable to discrete swash events, more typical on steeper beaches (Hughes and Baldock, 2004). Another physical process not included in the model is the beach permeability, i.e., 
infiltration/exfiltration into or out of the beach. However, these effects can be inherently incorporated via bed shear stresses. In the present study, the alongshore component is determined exclusively by the runup phase of swash motion: i.e., the backwash can therefore be ignored. Ignoring the alongshore component of the backwash phase associated with parabolic swash trajectories implies that sandtransport rates obtained from a saw-tooth model would be minimum estimates of longshore-drift.

The parametric model developed has a number of free parameters that provide greater freedom in the model but careful calibrations are required when applying to a site. Here, as a first approximation, some empirical values were adopted based on the similarities of related site-specific characteristics, i.e. beach slope, grain size, etc. The semi-empirical function (Eq.13) describing the swash depth involves two free parameters, $C$ and $D$, controlling the shape of the swash lens and the rate of thinning of the swash lens respectively. These parameters are expected to differ for particular beach slope and wave conditions. Sensitivity analysis showed that $C$ has relatively less effects on the velocity and duration than parameter $D$ (Hughes and Baldock, 2004). The coefficient $k$ in the Bagnold equation is found to vary between sites through the effect of grain size on the friction factor, however, to be independent of swash velocity and wave energy, and therefore is probably constant for a given site (Hughes et al., 1997). Further field data are needed to investigate the dependence of these parameters and to verify against a set of more comprehensive field conditions.

Previous studies have found that a significant part of the longshore sediment transport occurs in the swash zone and may account for a large portion of the total littoral drift (Bodge and Dean, 1987, Kamphuis, 1991, Smith et al., 2009), especially on steep reflective beaches (Van Wellen et al., 2000), where alongshore sediment transport in the swash zone can be significantly greater than that in the surf zone (Hughes et al., 2007). In the present study, model predicted alongshore swash-zone transport may account for $34 \%-100 \%$ of the total littoral drift under the wave conditions simulated at the study site. This confirms that longshore transport in the swash zone is not insignificant.

\section{CONCLUSIONS}

In this study, an existing process-based coastal model (MIKE 21) is combined with a theoretical derivation of swash processes, resulting in an innovative hybrid modelling approach that is capable of estimating longshore sediment transport in the swash zone. The modelling approach has been proved to be a useful method to estimate longshore sediment transport in the swash zone of steep reflective beaches. The model was applied to a study site and yielded the alongshore swash transport pathways as well as the indicative transport volumes. A point of transport divergence is identified at the beach erosion area, which is of critical importance in terms of shoreline erosion and management. The preliminary results also suggest that swash-zone transport can account for a large percentage of the total littoral drift for such beaches. However, further laboratory and field data are required to test model utility, as well as to tune the calibration parameters based on the site-specific conditions.

\section{ACKNOWLEDGMENTS}

This research has been funded by the Australian Research Council (ARC) in collaboration with the NSW Department of Environment and Climate Change (DECC), DHI Water \& Environment, Great Lakes Council, Port Stephens Council and Jimmy's Beach Restoration Society Inc. through Linkage Grant LP0668979.

\section{REFERENCES}

Bagnold, R. A. (1963) Mechanics of marine sedimentation. In: HillL M.N. (ed.), The Sea-Ideas and Observations. Wiley, New York, pp. 507-528.

Bagnold, R. A. (1966) An Approach to the Sediment Transport Problem from General Physics. United States Geological Survey Professional Paper, 422-I, 37pp.

Bakhtyar, R., Barry, D. A., Li, L., Jeng, D. S. \& Yeganeh-Bakhtiary, A. (2009) Modeling sediment transport in the swash zone: A review. Ocean Engineering, 36, 767-783.

Baldock, T. \& Holmes, P. (1997) Swash Hydrodynamics on a Steep Beach. In: Coastal Dynamics '97. New York, ASCE, 784- 793.

Baldock, T. E., Weir, F. \& Hughes, M. G. (2008) Morphodynamic evolution of a coastal lagoon entrance during swash overwash. Geomorphology, 95, 398-411.

Bodge, K. R. \& Dean, R. G. (1987) Short-term impoundment of longshore transport. In: Proceedings of Coastal Sediments '87. . New York, ASCE, 468-483. 
Bradshaw, M. P. (1980) Topographic control of run-up variablility. In: Proceedings 17th Coastal Engineering Conference. ASCE.

Butt, T. \& Russell, P. (2000) Hydrodynamics and Cross-Shore Sediment Transport in the Swash-Zone of Natural Beaches: A Review. Journal of Coastal Research, 16, 255-268.

Elfrink, B. \& Baldock, T. (2002) Hydrodynamics and sediment transport in the swash zone: a review and perspectives. Coastal Engineering, 45, 149-167.

Freeman, J. C. \& Lemehaute, B. (1964) Wave breakers on a beach and surges on a dry bed. Journal of the Hydraulics Division, Proceedings of the American Society of Civil Engineers, 90, 187216.

Hardisty, J. (1986) A morphodynamic model for beach gradients. Earth Surf, Processes Landforms 11, 3277333.

Hardisty, J., Collier, J. \& Hamilton, D. (1984) A calibration of the Bagnold beach equation. Marine Geology, 61, 95-101.

Ho, D. V., Meyer, R. E. \& Shen, M. C. (1963) Long surf. Marine Res, 1963, 21, 219-230.

Holland, K. T. \& Puleo, J. A. (2001) Variable swash motions associated with foreshore profile change. J. Geophys. Res., 106, 4613-4623.

Hughes, M., Aagaard, T. \& Baldock, T. (2007) Suspended Sediment in the Swash Zone: Heuristic Analysis of Spatial and Temporal Variations in Concentration. Journal of Coastal Research, 23 (6), 1345-1354

Hughes, M. \& Baldock, T. (2004) Eulerian flow velocities in the swash zone: field data and model predictions. Journal of Geophysical Research, 109.

Hughes, M., Masselink, G. \& Brander, R. (1997) Flow velocity and sediment transport in the swash zone of a steep beach. Marine Geology, Vol. 138, no. 1-2, pp. 91-103. Apr 1997.

Hughes, M. G. (1992) Application of a Non-Linear Shallow Water Theory to Swash following Bore Collapse on a Sandy Beach. Journal of Coastal Research, Vol. 8, No. 3, pp. 562-578.

Kamphuis, J. W. (1991) Alongshore sediment transport rate distribution. Proceedings Coastal Sediments '91, ASCE.

Kemp, P. H. (1975) Wave asymmetry in the nearshore zone and breaker area, Wiley, New York (1975), pp. 47-67.

Kirkgöz, M. S. (1981) A theoretical study of plunging breakers and their run-up. Coastal Engineering, 5, 353-370.

Larson, M., Kubota, S. \& Erikson, L. (2004) Swash-zone sediment transport and foreshore evolution: field experiments and mathematical modeling. Marine Geology, 212, 61-79.

Lord, D. \& Kulmar, M. (2000) The 1974 Storms Revisited: 25 Years Experience in Ocean Wave Measurement Along the South-East Australian Coast. IN: BILLY, L. E. (Ed.) Proceedings of the 27th Conference on Coastal Engineering. Sydney, ASCE.

Masselink, G. \& Hughes, M. (1998) Field investigation of sediment transport in the swash zone. Continental Shelf Research, 18, 1179-1199.

Masselink, G. \& Puleo, J. A. (2006) Swash-zone morphodynamics. Continental Shelf Research, 26, 661-680.

Meyer-Peter, E. \& Muller, R. (1948) Formulas for bed-load transport. 2nd Congress of the International Association for Hydraulics Structures Research. Stockholm, Sweden.

Nielsen, P. (2002) Shear stress and sediment transport calculations for swash zone modelling. Coastal Engineering, 45, 53-60.

Puleo, J. A., Beach, R. A., Holman, R. A. \& Allen, J. S. (2000) Swash zone sediment suspension and transport and the importance of bore-generated turbulence. J. Geophys. Res., 105, 1702117044.

Puleo, J. A. \& Holland, K. T. (2001) Estimating swash zone friction coefficients on a sandy beach. Coastal Engineering, 43, 25-40.

PWD (1987) Jimmys Beach Erosion Study. PWD NSW Report No. 85042.

Raubenheimer, B., Elgar, S. \& Guza, R. T. (2004) Observations of swash zone velocities: A note on friction coefficients. J. Geophys. Res., C01027, 109.

Raubenheimer, B., Guza, R. T., Elgar, S. \& Kobayashi, N. (1995) Swash on a gently sloping beach. J. Geophys. Res., 100, 8751-8760.

Shen, M. C. \& Meyer, R. E. (1963) Climb of a bore on a beach: Part three run-up. Journal of Fluid Me-chanics, 16, 113-125. 
Short, A. D. \& Trenaman, N. L. (1992) Wave Climate of the Sydney Region, an Energetic and Highly Variable Ocean Wave Regime. Australia Journal of Marine and Freshwater Research, 43, 26.

Smith, E. R., Wang, P., Ebersole, B. A. \& Zhang, J. (2009) Dependence of Total Longshore Sediment Transport Rates on Incident Wave Parameters and Breaker Type. Journal of Coastal Research, 25, 675-683.

Sunamura, T. (1984) Quantitative prediction of beach face slopes. Geol. Sot. Am. Bull, 95, 242-245.

Turner, I. L. (1995) Simulating the influence of groundwater seepage on sediment transported by the sweep of the swash zone across macro-tidal beaches. Mar. Geol., 125, 153-174.

Van Wellen, E., Baldock, T., Chadwick, A. \& Simmonds, D. (2000) STRAND - a Model for Longshore Sediment Transport in the Swash Zone. Proceedings of the 27th Conference on Coastal Engineering. Sydney, ASCE, 3139-3150.

Wright, L. D. \& Short, A. D. (1984) Morphodynamic variability of surf zones and beaches: a synthesis. Mar. Geol., 93-118.

Yeh, H. H., Ghazali, A. \& Marton, I. (1989) Experimental study of bore run-up. Journal of Fluid Mechanics Digital Archive, 206, 563-578. 